\title{
Dynamic Simulation and Optimization of an Off- grid Solar Photovoltaic Driven Drinking Fountain with Battery Storage
}

\author{
Roberta P. S. Souza, Luis G. G. K. Gesteira, and Antonio G. S. Almeida*
}

\begin{abstract}
This paper presents a case study involving the design and energy saving analysis of an off-grid solar photovoltaic driven drinking fountain with battery storage. A dynamic simulation in TRNSYS software is performed to model and evaluate the transient processes occurring in this renewable system. A sensitivity analysis of the main design parameters, power generation capacity and electric storage capacity, was performed in order to optimize the scheme. The case study was carried out at Federal Institute of Education, Science and Technology of Bahia in Salvador, in the northeast of Brazil. The temperature profiles and electrical energy flows of the optimized system are investigated by means of a daily, weekly and yearly analysis. The outcomes achieved show that the optimized system showed a $33.3 \%$ increase in thermal efficiency and $15.1 \%$ increase in the global efficiency in relation to the base case. This system was able to produce $5932.7 \mathrm{~L}$ of chilled water per year and a $65626.8 \mathrm{Wh}$ reduction of primary energy consumption per year. This study can be applied to universities, schools or places with large flow of people.
\end{abstract}

Index Term-solar photovoltaic; renewable energy; solar cooling; sensitivity analysis; dynamic simulation.

\section{INTRODUCTION}

$\mathrm{I}$ ndustrialization, population increase and consumer habits are the main factors responsible for the growth in world energy demand and everything indicates that this will continue to grow in the future. In this century, it has doubles every 14.5 years $[1,2]$. This increase contributes to the rapid reduction of fossil fuels and has negative environmental effects (pollution, global warming, depletion of the ozone layer etc.), leading to the need for studies, investment and expansion in sources of clean and renewable energy [35].

In this context, solar energy has the highest potential compared to other renewable energy sources since the sun is an unlimited source of energy for the planet Earth.

Manuscript received October 20, 2020, revised November 2020, accepted April 15, 2021

Roberta P. S. Souza is with Campus of Salvador, Institute Federal of Bahia, (e-mail: robertapenina1994@gmail.com)

Luis G. G. K. Gesteira is with Campus of Salvador, Institute Federal of Bahia, (e-mail: luis.gesteira@ifba.edu.br)

Antonio G. S. Almeida is with Campus of Salvador, Institute Federal of Bahia, (e-mail: gabrielalmeida@ifba.edu.br)

*Corresponding author.
Approximately four million exajoules per year of solar energy reaches the earth, of which $5 \times 10^{4}$ EJ can be easily harvestable [6]. Solar energy technologies can be divided into passive (direct, indirect or isolated solar gain) and active (photovoltaic, solar thermal and concentrated solar power) in which Photovoltaic (PV) technologies are the most widespread.

This is because PV technology is simple to design and install, offers minimal maintenance, has a low operational cost, besides being non-pollutant, reducing global warming and falling in installation price in recent years [7-10] . However, this technology cannot provide electricity continuously during all hours of a day due the intermittency of solar radiation, requiring the use of energy storage systems [11].

For power system applications, lead-acid batteries are the most widely used energy storage technology compared to other energy storage systems such as flywheel storage, supercapacitor storage, thermal energy storage, compressed air energy storage etc $[12,13]$. This is because lead-acid batteries have a low cost $(\$ 300-600 / \mathrm{kWh})$, high efficiency $(65$ $80 \%$ ) and can supply power on demand without delay $[14,15]$. Battery storage systems accept co-generated and/or third-party power and can respond very rapidly to a shift in the load, improving the system stability and bringing benefits to the electricity utility, since stability problems in the grid network may occur due the intermittent nature of renewable energies [16,17].

PV technologies can have many applications, one of which is solar PV cooling systems [18]. These systems consist mainly of electronics of regulation (battery, inverter for example), photovoltaic modules and an electrical refrigeration device, in which vapor compression cooling systems is the most widespread technology in the air conditioning and refrigeration market [19-22]. The advantages of using these systems lie in the fact that they can achieve a high overall efficiency and substantial energy savings, since air-conditioning and refrigeration processes consume approximately $15 \%$ of all the electrical energy produced worldwide, according to The International Institute of Refrigeration in Paris [23-25].

To evaluate solar PV cooling systems, many papers have been published on several aspects and from various perspectives. However, the main investigated application is in the field of HVAC systems. Liu et al. [26] conducted an analysis in the working principle of quasi grid-connected energy-saving technology. They carried out experimental tests using a conventional air conditioner and an economic analysis to investigate the principle and composition of an air conditioner driven by a quasi-grid-connected PV system. The results showed that the system studied can conserve more than $67 \%-77 \%$ of grid electricity, the EER value can be 4.6 times 
higher than that of a conventional air conditioner and paying back the cost can take 4.5 years if the system is used in large establishments such as supermarkets or restaurants. Goldsworthy [27] carried out a detailed simulation model to analyze the capability of an off-grid PV battery driven airconditioner system to provide occupant comfort for different building thermal designs for 69 climate zones across Australia. The obtained results showed that $100 \%$ comfort can be obtained for certain building and climate combinations, with a modest size system. Li et al. [28] analyze the operational performance of a grid-connected photovoltaic-powered central chiller system for an office building in South China. The operation characteristics were analyzed in terms of net solar fraction (NSF), solar fraction (SF) and surplus energy ratio (SER) and the yearly average values obtained were $104.5 \%, 51.62 \%$ and $52.72 \%$ respectively. In an experimental study of an office building in Alicante (Spain), Aguilar et al. [29] investigated an air conditioning unit simultaneously powered by the grid and solar panels without the use of batteries or inverter regulators. The experimental results show that the average EER and average COP of the system is around 14 and 9, and the solar contribution of PV panels is about $65 \%$ and $50 \%$ in the summer months and heating mode, respectively. Li et al. [30] present an experimental study to evaluate the operation performance of a solar photovoltaic air conditioner for the typical hot summer and cold winter conditions of China. The system can be installed in office buildings or in residential buildings and can be applied as stand-alone or grid-connected. The results showed that, for these weather conditions, the system can meet the cooling/heating load at different peak times. Chen et al. [31] conducted research into a design method for a PV direct-drive air conditioning system for an office building in hot-humid regions. The authors also investigated the cooling performance of the system through experimental tests. They concluded that the power generation capacity of the system can be self-sufficient, without the grid supplement. Novaes Pires Leite et al. [32] carried out economic viability analyses, through a mathematical model, considering the integration between solar photovoltaic systems and air-conditioning. Variable refrigerant flow systems and chiller systems were analyzed, with irradiation and temperature at various levels, in Recife and São Paulo in Brazil. A sensitivity analysis, using the SOBOL method, of the Internal Rate of Return, IRR, Payback Period, PBP, and Net Present Value, NPV, was performed for the case studies. The obtained results showed high values of IRR and NPV and low values for PBP, indicating the great viability of the implementation of HVAC systems with solar PV energy.

From the previous literature review, it can be noted that there is no study into a vapor compression cooling system applied to an off-grid solar PV driven drinking fountain with battery storage, and this paper addresses this gap to provide a design analysis, through a case study, of such a system. A dynamic simulation in TRNSYS software is performed to model and evaluate the transient processes occurring in this renewable system. Then, a sensitivity analysis is made in order to assess the performance and provide an optimization of the studied system.

The case study was carried out at the Federal Institute of Education, Science and Technology of Bahia in Salvador, in the northeast of Brazil, where there is an Internal Environmental Sustainability Commission (CISA), made up of students, teachers and administrative technicians, who promote and disseminate actions and projects promoting environmental sustainability. The off-grid solar photovoltaic driven drinking fountain with battery storage was implemented on site to reduce the cost of electricity generation and greenhouse gas emissions.

The outcomes achieved in this paper can be useful in providing a detailed study on a renewable energy system for application at universities, schools or in places where there is a large circulation of people.

\section{SYSTEM CONFIGURATION}

The system is made up of a power loop, a thermal loop and controllers, which are the link between the two subsystems. The system scheme is shown in Fig. 1.

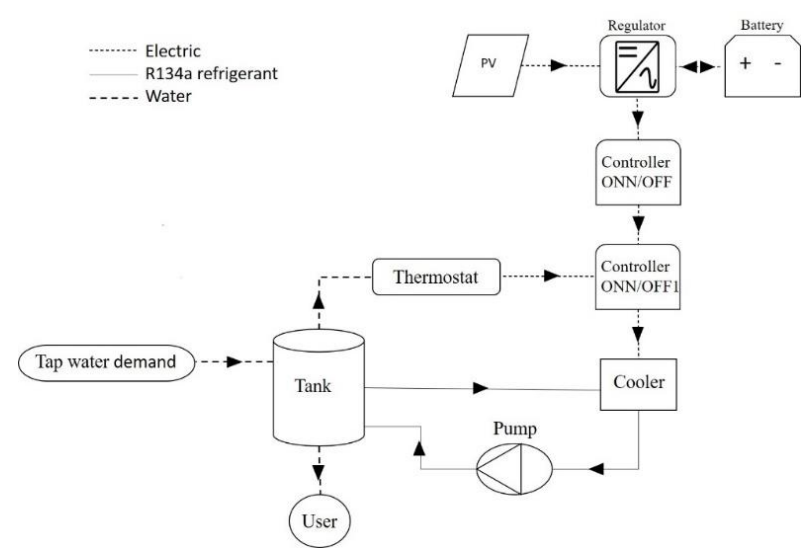

Fig. 1. General description of the off grid renewable system.

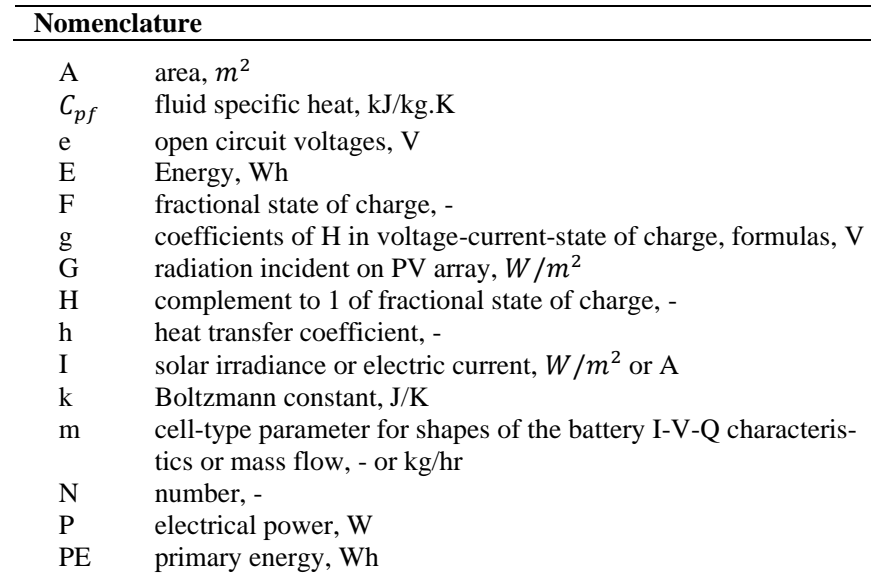




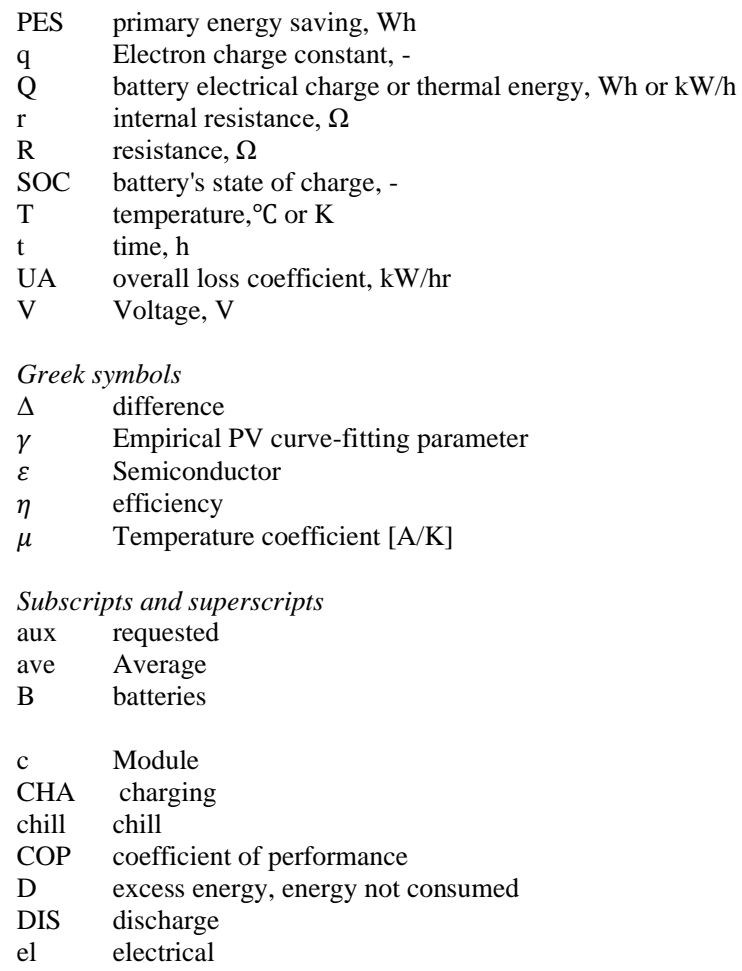

$\begin{array}{ll}\text { env } & \text { referred to surroundings } \\ \text { final } & \text { at the end of the timestep } \\ \text { fluid } & \text { fluid stream } \\ \text { G } & \text { referred to electrical grid } \\ \text { HL } & \text { high limit, when battery charging } \\ \text { htr } & \text { auxiliary cooler } \\ \text { hx } & \text { referred to heat exchanger } \\ \text { i } & \text { inner } \\ \text { in } & \text { input } \\ \text { initial } & \text { at the beginning of the timestep } \\ \text { isc } & \text { short-circuit current } \\ \text { L } & \text { demanded by load } \\ \text { LI } & \text { limit, above which battery can begin to discharge after being } \\ & \text { charged } \\ \text { LM } & \text { Module photocurrent } \\ \text { LO } & \text { low limit, when battery discharging } \\ \text { loss } & \text { losses } \\ \text { m } & \text { maximum capacity of the battery } \\ \text { max } & \text { maximum } \\ \text { mod } & \text { referred to photovoltaic modules } \\ \text { Mp } & \text { at maximum power point along IV curve } \\ \text { n } & \text { effective } \\ \text { NO } & \text { node } \\ \text { O } & \text { Diode reverse saturation } \\ \text { oc } & \text { Open-circuit } \\ \text { ou } & \text { outer } \\ \text { Pb } & \text { output } \\ \text { SS } & \text { propitions and acronyms } \\ \text { qc } & \text { full charge when charging } \\ \text { wt } & \text { full charge when discharging } \\ \text { Ref } & \text { at reference conditions } \\ \text { S } & \text { Module series } \\ \text { SC } & \text { Short-circuit } \\ \text { set } & \text { Setpoint } \\ \text { Tank } & \text { referred to storage tank } \\ \text { Tot } & \text { Total } \\ \text { tube wall } \\ \end{array}$

\section{A. Power Loop}

The power loop is made up of photovoltaic modules, a regulator and a battery bank. The power is generated by two photovoltaic modules, $140 \mathrm{Wp}$ each one, connected in parallel. This power is driven to a regulator which is responsible for conducting the electric load and the charge or discharge of the battery. The battery bank consists of two lead-acid batteries of 170Ah and $12 \mathrm{~V}$ each, and these are responsible for supplying the power supply when the power generated by the photovoltaic modules is not enough or not possible.

The electric load is composed of the power required by the thermal loop, $148 \mathrm{~W}$. This power is set by a schedule that establishes that its operation can only be between $7 \mathrm{am}$ and $9 \mathrm{pm}$ on weekdays and from 7am to 12am on Saturdays. At any other time, the thermal loop is off. Any remaining power is stored in the batteries, if necessary, it is used, or not. 


\section{B. Thermal Loop}

The storage tank has a capacity of $100 \mathrm{~L}$ and is fed with two flow streams. One flow stream consists of the R134a refrigerant, which is sent to the heat exchanger inside the tank by means of a cooler/pump system with a flow rate of $4.8 \mathrm{~L} / \mathrm{h}$. The other flow stream consists of the tap-water consumption, temperature according to the dew point, sent to the tank by a flow controller. The tank is also connected to a thermostat, which regulates the water outlet temperature to the user at between $10^{\circ} \mathrm{C}$ and $14^{\circ} \mathrm{C}$.

\section{Controllers}

The controllers are the link between the Power loop and the Thermal loop. The controller ON/OFF is responsible for ensuring that the system is off grid. To do this, the controller establishes that the electricity supply is provided only by power from the photovoltaic array and/or power from the batteries, without interference from the power grid. The controller ON/OFF1 is responsible for deciding when to turn the thermal loop on or off. This operation depends on the response of the controller ON/OFF and the thermostat.

The thermal loop is therefore powered only when two conditions are met. The first condition is that electricity supply must come directly from the photovoltaic modules and/or from battery bank, and the second condition is that tank water outlet temperature must be above $14^{\circ} \mathrm{C}$. The system control strategy is shown in Fig. 2.

\section{SIMULATION MODEL}

All dynamic simulations were performed in TRNSYS (Transient System Simulation), such as the unification of the subsystems shown in section 2. TRNSYS software is a dynamic simulation tool that includes a library of built-in components (HVAC, Electrical, Thermal Storage) often validated by experimental data.

The dynamic simulation can locate possible mistakes in the preliminary system design and consequently perform the optimization of the parameters and components in order to find the best configuration for the proposed system. To perform the dynamic simulation project, shown in Figure 3, logical and physical connections (power, temperature, mass flow...) are created through the links between the components (all the components were taken from the software library, shown in Table I. For sake of brevity, only the main system components are described below.

TABLE II. COMPONENTS SIMULATED IN TRNSYS

\begin{tabular}{cc}
\hline Components & Type \\
\hline Weather data & $15-6$ \\
PV array & $94 \mathrm{a}$ \\
Regulator & 48 \\
Battery & 47 \\
Schedule & $41 \mathrm{c}$ and $14 \mathrm{~h}$ \\
Cooler & 92 \\
Pump & 114 \\
Tank & 534 \\
Controller & 2 \\
Water Consumption & $14 \mathrm{~b}$
\end{tabular}

\section{A. Sola Photovoltaic Model}

Type 94a models the electrical performance of a polycrystalline PV modules, by means of a "four-parameter" equivalent circuit model [33]. This equivalent circuit model is determined using manufactures' values to find the PV performance at each timestep Module photocurrent at reference conditions $\left(I_{L, r e f}\right)$, Diode reverse saturation current at reference conditions $\left(I_{O, r e f}\right)$, Empirical PV curve-fitting parameter $(\gamma)$ and Module series resistance $\left(R_{S}\right)$ are the "four parameter" model, which assumes that the slope of the IV curve is zero at the short-circuit condition. These parameters are calculated as follows:

The current-voltage equation:

$$
I=I_{L M}-I_{O}\left[\exp \left(\frac{q}{\gamma k T_{C}}\left(V+I R_{S}\right)\right)-1\right]
$$

The photocurrent $I_{L}$ equation:

$$
I_{L M}=I_{L M, \text { ref }} \frac{G_{T o t}}{G_{T o t, r e f}}
$$

The diode reverse saturation current, $I_{O}$ :

$$
\frac{I_{O}}{I_{o, \text { ref }}}=\left(\frac{T_{c}}{T_{c, r e f}}\right)^{3}
$$

From equations 1, 2 and $3 I_{L M}$ and $I_{O}$ are found. After that, the PV current is calculated from Newton's method. The Current and Voltage at maximum power point along IV curve, $I_{m p}$ and $V_{m p}$ respectively, are found by an iterative search routine.

Considering some rearrangement and substituting the current and voltage at the open-circuit, short circuit, and maximum power conditions into equation $2, I_{L M, r e f}, I_{O, \text { ref }}$ and $\gamma$ are isolated by the following three expressions:

$$
\begin{gathered}
I_{L M, r e f} \approx I_{s c, r e f} \\
\gamma=\frac{q\left(V_{m p, r e f}-V_{o c, r e f}+I_{m p, r e f} R_{S}\right)}{k T_{c, r e f} \ln \left(1-\frac{I_{m p, r e f}}{I_{s c, r e f}}\right)} \\
I_{o, \text { ref }}=\frac{I_{s c, r e f}}{\exp \left(\frac{q V_{o c, r e f}}{\gamma k T_{c, r e f}}\right)}
\end{gathered}
$$

The analytical derivative of voltage with respect to temperature at the reference open-circuit condition is used to find an additional equation to determine the last unknown parameter:

$\frac{\partial V_{o c}}{\partial T_{c}}=\mu_{v o c}=\frac{\gamma k}{q}\left[\ln \left(\frac{I_{s c, r e f}}{I_{o, r e f}}\right)+\frac{T_{c} \mu_{i s c}}{I_{s c, r e f}}-\left(3+\frac{q \varepsilon}{\frac{\gamma}{N_{S}} k T_{c, r e f}}\right)\right]$

Finally, the equivalent circuit characteristics are calculated using an iterative search routine in these four equations [34].

\section{B. Regulator Model}

The component modelled in here is the regulator, which is a power conditioning device that distributes DC power from the solar photovoltaic array to and from a battery. Type 48 works with type 47 , monitoring the battery's State Of Charge, SOC. To do this, the SOC is tested against several parameters [35]. 


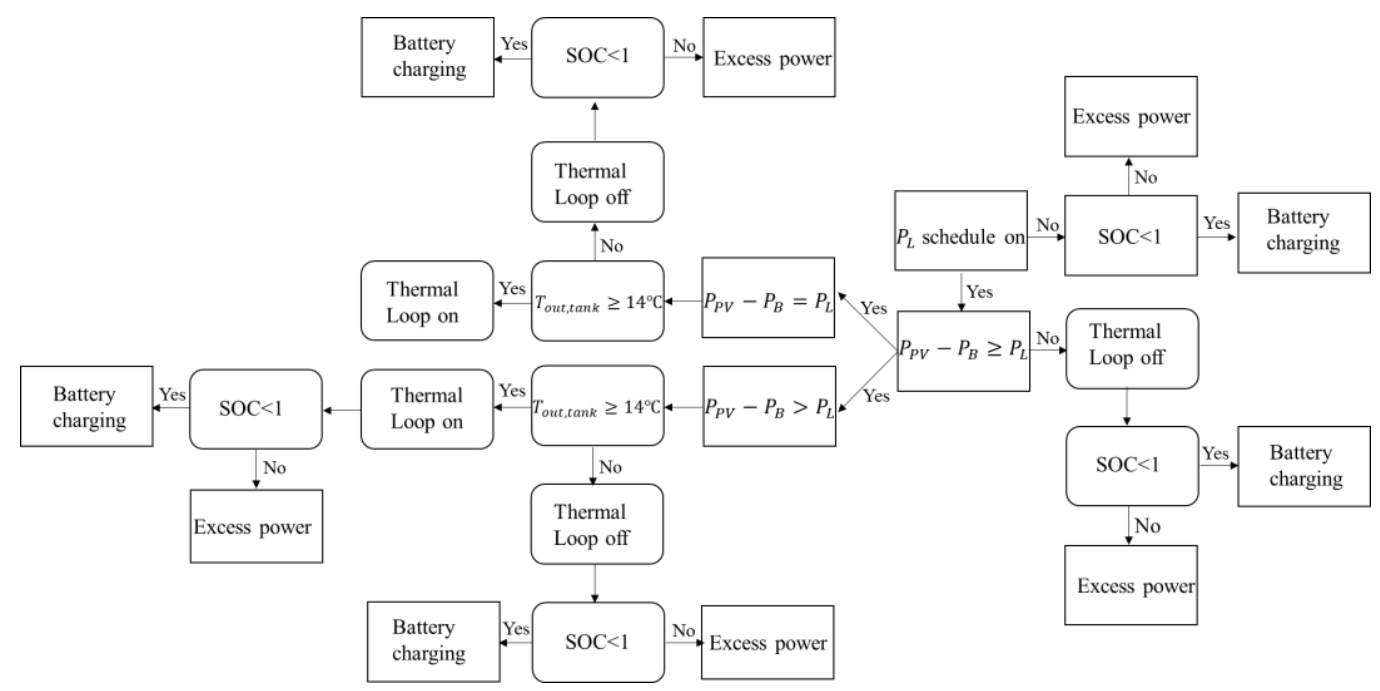

Fig. 2. System operating strategies.

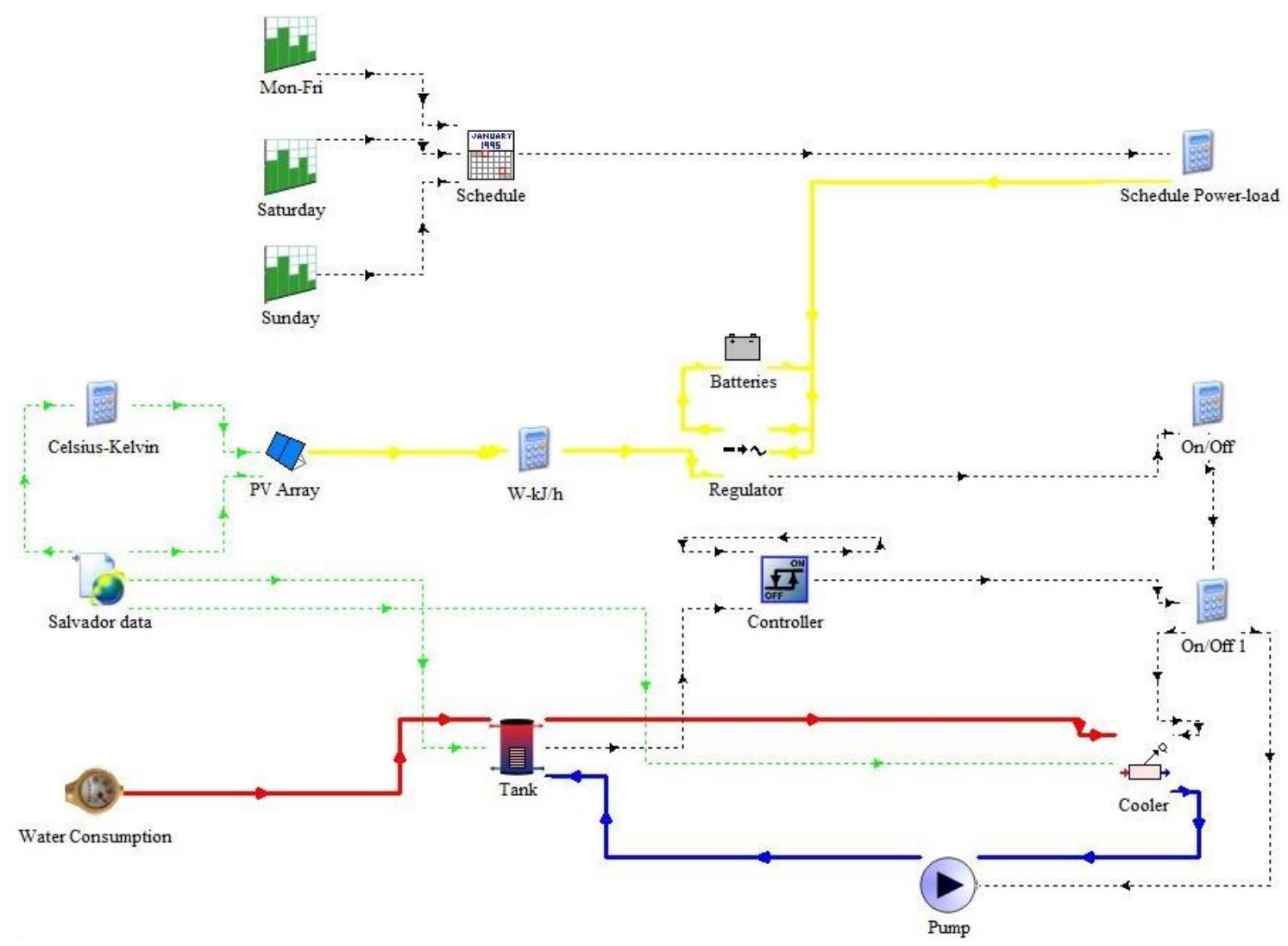

Fig. 3. Full project created in TRNSYS

Firstly, if the high limit on state of charge, $S O C_{H L}$, is greater than the state of charge the battery can discharge (when the power from solar photovoltaic array, $P_{P V}$, is lower than power demanded by load, $P_{L}$ ), or be charged (when $P_{P V}$ is greater than $P_{L}$ ). It is also determined if the state of charge is lower than the limit on the stage of charge, $S O C_{L I}$, above which the battery can begin to discharge after being charged. If these two conditions are met, the battery is on "total charge". In this status, any array output is devoted to recharging the battery, as first priority, instead of sending the output to the power load until $S O C$ is greater than $S O C_{L I}$.
By setting the low limit on state of charge when battery is discharging, $S O C_{L O}$, greater than $S O C_{L I}$, any array output is given to meet the power load, as first priority. If $S O C_{L I}$ is lower than $S O C$ or the battery is discharging, the battery bank can discharge (when $P_{P V}$ is lower than $P_{L}$ ), or be partially charged (when $P_{P V}$ is greater than $P_{L}$ ). Finally, to ensure that $S O C_{L O}$ is lower than $S O C$ a check is made, and if $S O C_{L O}$ is greater than $S O C$ no further discharging is allowed. The regulator control strategy described, is shown in Fig. 2 [34]. 


\section{Battery Model}

This component models a lead-acid storage battery that operates in conjunction with the PV array and the regulator. Given the rate of charge or discharge, this model describes what the variation of the battery state of charge is. The mathematic model of the battery is based on Shepherd equations, which describe the battery discharge or charge[35]. The formula of the battery discharge $(\mathrm{I}<0)$ is given by

$$
V=e_{q d}-g_{D I S} H+I r_{q d}\left(1+\frac{m_{D I S} H}{\frac{Q_{D I S}}{Q_{m}}-H}\right)
$$

And the formula of the battery charge $(\mathrm{I}>0)$ is given by:

$$
V=e_{q c}-g_{C H A} H+I r_{q c}\left(1+\frac{m_{C H A} H}{\frac{Q_{C H A}}{Q_{m}}-H}\right)
$$

A null value of current is never set by the regulator, which works connected to the battery. Rather, when discharge or charge is not allowed by the conditions at cutoff voltage and on fractional state of charge, when battery is discharging/charging, the regulator grants the current some small negative or positive value, depending on what would be the desired conditions (discharging or charging), if permitted.

In order to extend the battery life, the voltage values of maximum charging and minimum discharging voltages are limited. The value at which appreciable gassing of the battery electrolyte initiates must be higher than the maximum charge voltage limit [34]. While, the cutoff voltage on discharge, $V_{D I S}$, is given by:

$$
V_{D I S}=e_{D I S}-|I| r_{D I S}
$$

Ultimately, the variation in the battery charge is given by:

$$
\frac{d Q}{d t}=\left\{\begin{array}{lc}
I & \text { if } I<0 \\
I . \eta_{C H A} & \text { if } I>0
\end{array}\right\}
$$

\section{Cooler Model}

Type 92 models a cooler that works by removing heat from the R134a flow rate at a determined maximum cooling rate, $Q_{\text {max }}$, whenever the set temperature, $T_{\text {set }}$, is lower than cooling unit outlet temperature and the external control signal, $C_{s}$, is equal to 1 .

If the fluid inlet temperature, $T_{i n}$, is higher than or equal to $T_{s e t}$, inlet fluid mass flow rate, $\dot{m}_{i}$, is higher than zero or $C_{s}$ is equal to one, an energy balance is achieved as follows:

The fluid outlet temperature, $T_{\text {out }}$, is calculated from:

$$
\begin{gathered}
T_{\text {out }} \frac{\dot{Q}_{m a x} \eta_{h t r}+\dot{m} C_{p f} T_{i n}+U A T_{e n v}-\frac{U A T_{i n}}{2}}{\dot{m} C_{p f}+\frac{U A}{2}} \\
\dot{m}_{\text {out }}=\dot{m}_{\text {in }}=\dot{m} ; \dot{Q}_{a u x}=\dot{Q}_{\text {max }}
\end{gathered}
$$

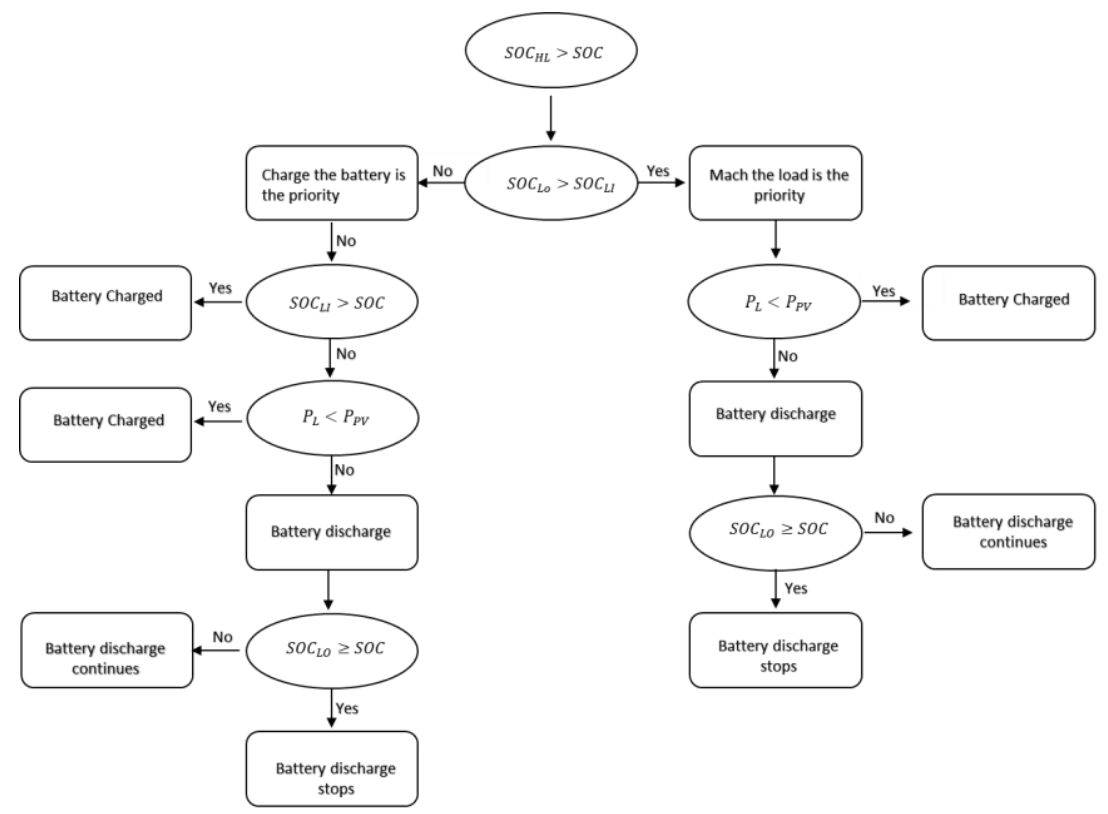

Fig. 4. Regulator control strategy.

The rate of heat removal from the fluid stream, $\dot{Q}_{\text {fluid }}$, and the rate of thermal loss from the cooler to the environment, $\dot{Q}_{\text {loss }}$, is calculated from equations 13 and 14, respectively:

$$
\begin{gathered}
\dot{Q}_{\text {fluid }}=\dot{m}_{\text {out }} C_{p f}\left(T_{\text {in }}-T_{\text {out }}\right) \\
\dot{Q}_{\text {loss }}=U A\left(\frac{T_{\text {out }}+T_{\text {in }}}{2}-T_{\text {env }}\right)+\left(1-\eta_{\text {htr }}\right) \dot{Q}_{\max }
\end{gathered}
$$

Finally, $T_{O}$ becomes $T_{\text {set }}$ in equations 13 and 14 if the fluid outlet temperature is lower than the set temperature [34]. From this, the required cooling rate is calculated from:

$$
\dot{Q}_{a u x}=\frac{\dot{m} C_{p f}\left(T_{s e t}-T_{i n}\right)+U A\left(\frac{T_{s e t}+T_{i n}}{2}-T_{e n v}\right)}{\eta_{h t r}}
$$

\section{E. Tank Model}

Type 534 models a constant volume stratified storage tank with an immersed heat exchanger. In this component the water within the tank interacts with the R134a refrigerant in the heat exchanger, with the environment and with one flow stream that enters the storage tank. To model stratification the tank is divided into isothermal temperature constant 
volume node. In this storage tank, heat can be transferred into and out through two unique flow streams [36]. The storage fluid mixes with one of the fluid streams, while through an immersed heat exchanger, the another fluid stream transfers heat to or from the storage tank [37]. The differential equations that represent this system are given by:

$$
\begin{aligned}
& \frac{d T_{\text {tank }}}{d t}=\frac{\left(Q_{\text {in }, \text { tank }}-Q_{\text {out }, \text { tank }}\right)}{C_{\text {tank }}} \\
& \frac{d T_{h x}}{d t}=\frac{\left(Q_{\text {in }, h x}-Q_{\text {out }, h x}\right)}{C_{h x}}
\end{aligned}
$$

An approximate analytical solution was the method chosen to solve the coupled differential equations. To do this, the equations are put into the form:

$$
\frac{d T}{d t}=a T+b
$$

If $b$ is not constant, then by assuming that $b$ is equal to its average value over the timestep and it is also a constant over the timestep, a reasonable approximation to the analytical solution can be found, since in TRNSYS simulations a small timesteps is used (maximum timestep $=1$ hour).

For $a \neq 0$ at any time:

$$
T_{\text {final }}=\left(T_{\text {initial }}+\frac{b_{\text {ave }}}{a}\right) e^{(a \Delta t)}-\frac{b_{\text {ave }}}{a}
$$

Where

$$
b_{\text {ave }}=b\left(T_{\text {ave }}\right)
$$

And:

$$
T_{\text {ave }}=\frac{1}{a \Delta t}\left(T_{\text {initial }}+\frac{b_{\text {ave }}}{a}\right)\left(e^{(a \Delta t)}-1\right)-\frac{b_{\text {ave }}}{a}
$$

The outer surface of the heat exchanger interacts thermally with the tank fluid through natural convection heat transfer. In this case, the overall heat transfer coefficient (UA) can be expressed as:

$$
\frac{N}{U A}=\frac{1}{h_{o u} A_{o u}}+R_{w t}+\frac{1}{h_{i} A_{i}}
$$

The heat transfer between the heat exchanger node $(\mathrm{k})$ and the tank node $(\mathrm{j})$ is calculated as follows:

$$
Q_{h x, j \rightarrow k}=U A_{j, k}\left(T_{\text {tank,j}}-T_{h x, k}\right)
$$

Besides the heat transfer to the storage tank fluid, there is a heat transfer via the fluid flow, $Q_{\text {fluid }}$, through the heat exchanger:

$$
Q_{\text {fluid }}=\dot{m} C_{p f}\left(T_{h x, k}-T_{\text {in }}\right)
$$

Finally, also considered in this model are the thermal losses to the environment through the top, sides and bottom of the storage tank, heat exchange with flowing and stagnant fluid in the heat exchanger, conduction between adjacent tank nodes, mixing between nodes, due to the load flow through the storage tank and eliminating thermal instabilities [34].

\section{PERFormance PARAMETERS}

As the main goal of the simulation of the proposed system is the optimization of electrical energy generation and storage as a function of the thermal performance. The evaluation criterion is based on two efficiency factors, the first is the Electric system factor, $\eta_{e l}$, and the other is the Thermal system factor, $\eta_{t h}$.

The Electric system factor is responsible for analyzing how efficient the use of electrical energy produced by the photovoltaic panels is. This factor is calculated by:

$$
\eta_{e l}=100\left(1-\frac{P_{D}}{P_{P V}}\right)
$$

The thermal system factor analyzes the ability of the proposed system to maintain the water temperature for the user within the limits required, which is from $10^{\circ} \mathrm{C}$ to $14^{\circ} \mathrm{C}$. This factor is calculated as follows:

$$
\begin{gathered}
Q_{n, \text { tank }}=\dot{m}_{\text {tank }} C_{p f}\left(T_{\text {out }, \text { tank }}-T_{\text {set,tank }}\right) \\
Q_{\text {aux }, \text { tank }}=\dot{m}_{\text {tank }} C_{p f}\left(T_{\text {in,tank }}-T_{\text {set,tank }}\right) \\
\eta_{\text {th }}=100\left(1-\frac{Q_{n}}{Q_{d}}\right)
\end{gathered}
$$

The system global efficiency, $\eta_{\text {global }}$, is also calculated which analyzes the combined effect of $\eta_{e l}$ and $\eta_{t h}$ in the proposed system, in which the $\eta_{t h}$ plays a greater role. This factor is given by:

$$
\eta_{\text {global }}=\frac{\left(1 \eta_{e l}+2 \eta_{t h}\right)}{3}
$$

The proposed system performance is also evaluated in terms of energy savings. To do this, a comparison between the Proposed System (PS) and the Standard one (SS) is performed.

The SS consists of an electric drinking fountain for the provision of chilled water installed in the same place as the PS, with a coefficient of performance in cooling mode $C O P_{\text {chill }}=1.7$ [38]. An electrical efficiency factor, $\eta_{e l, G}=$ 0.8471 [39], for electric load of the SS, supplied by the national electric grid is considered.

To perform a correct energetic comparison, for both PS and SS the same water consumption demand pattern is used with the same set point of temperature for the user.

The Primary Energy Saving (PES) achieved by PS with regard to $\mathrm{SS}$ is given by:

$$
P E S=P E_{S S}-P E_{P S}
$$

Where PS is an off-grid system, equation 29 can be expressed as:

$$
P E S=P E_{S S}
$$

Where:

$$
P E_{S S}=\frac{Q_{\text {tank }, T o t}}{\operatorname{COP}_{\text {chill }} \eta_{e l, G}}
$$

\section{Case Study}

The case study (base case) consists of an off grid solar photovoltaic driven vapor compression cooling system implemented at the Institute Federal of Education, Science and Technology of Bahia (IFBA) located in Salvador, in the northeast of Brazil. This system is designed to supply chilled water to students, teachers and staff at IFBA.

Meteonorm weather data for Salvador was implemented 
for the simulation of the climatic conditions and the tap-water demand considered in this investigation was measured by an Arduino data acquisition system installed in the real renewable energy system. In order to build the tap-water consumption demand pattern shown in Figure 5, a weekly average was made with 1,440 pieces of data collected per day for about 2 months.

The simulations results of the proposed system are highly reliable, since all the design and operational parameters of the system are taken from manufacturer's data and/or chosen accordingly to literature, taking into account real values and aspects of the renewable energy installation. For the sake of brevity, only the main system operational parameters are reported in Table II.

\section{RESULTS}

The dynamic simulation developed in this paper was performed for the entire year (from $0 \mathrm{~h}$ to $8,760 \mathrm{~h}$ ) with a time step of $0.5 \mathrm{~h}$. As mentioned before, the main goal of this study is to provide the best design of the proposed system. A sensitivity analysis was made in order to evaluate the system performance as a function of the main design parameters: power generation capacity and electric storage capacity.

After that, the dynamic behavior of the system with the best performance is analyzed in terms of temperature profiles and electrical energy flows for a representative winter and summer day. In order to better present the variation in the chosen parameters a weekly and annual basis are also adopted.

\section{A. Sensitivity Analysis}

In order to improve the base case a sensitivity analysis was performed, varying the number of PV modules and batteries to assess the system performance through the efficiency factors of the proposed system: $\eta_{e l}, \eta_{t h}$ and $\eta_{\text {global }}$. TRNEdit tool of TRNSYS was used to perform this analysis.

The number of PV modules and batteries ranged from 1 to 8 for the three efficiency factors as shown in Figures 6,7 and 8 . In this scenario, $\eta_{t h}$ and $\eta_{e l}$ behave differently with respect to: 1 . The variation in the number of PV modules and 2 . The variation in the number of batteries.

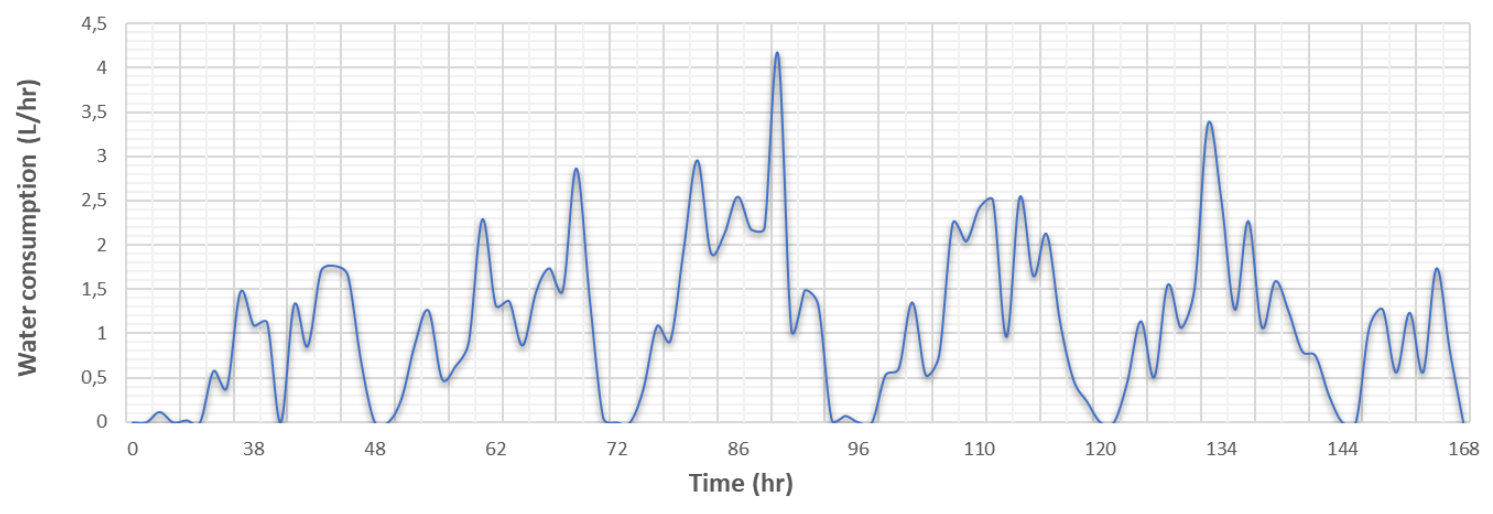

Fig. 5. Water consumption demand pattern.

TABLE II. MAIN OPERATIONAL PARAMETERS

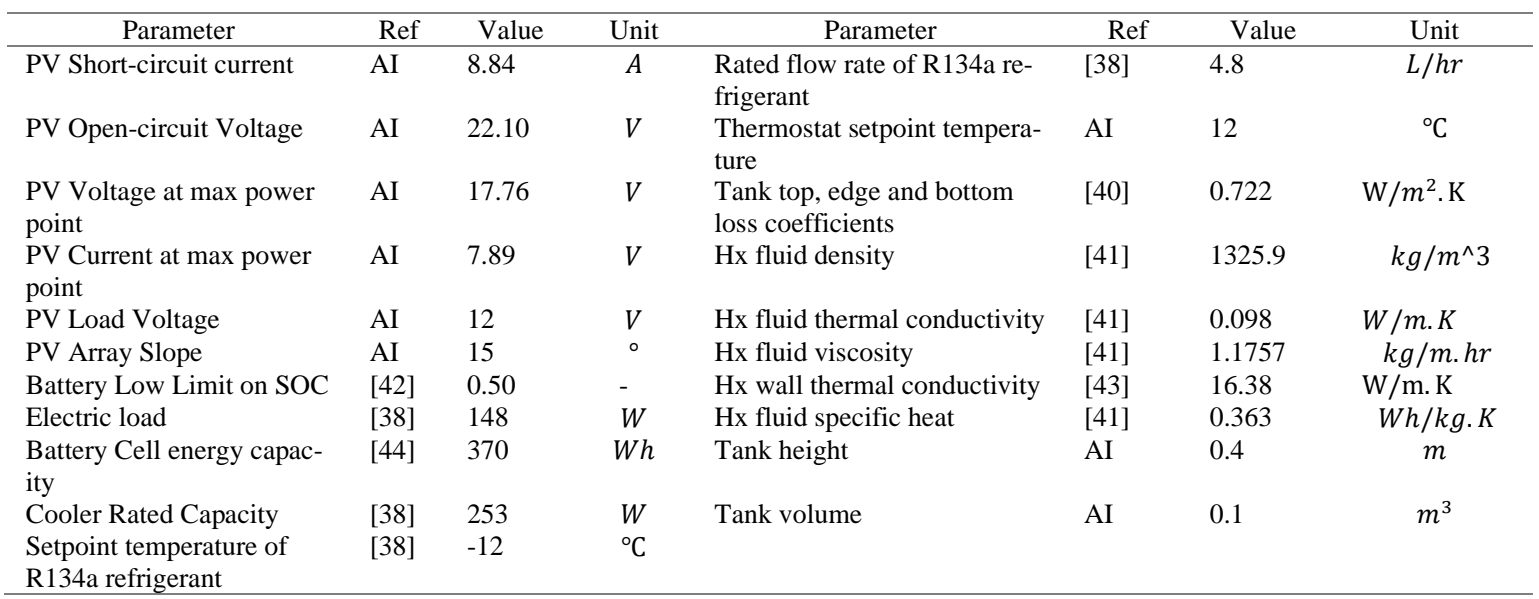

Concerning the variation in the number of PV modules, $\eta_{e l}$ decreases with the increase in the number of PV modules because with the fixed electric load an increase in the number of PV modules means more power generation, but it also means more power wasted. The $\eta_{t h}$ grows with the increase in the number of PV modules until the power generation becomes sufficient to maintain, in daylight hours, the water temperature for the user within the limits required, after that, this factor remains constant.

Regarding the variation in the number of batteries, $\eta_{e l}$ grows with the increase in the number of batteries, this occurs because more energy is needed to charge a higher number of batteries. The $\eta_{t h}$ grows with the increase in the number of batteries until the battery bank reaches its full capacity 
in maintaining the temperature of the water leaving the tank to the user within the limits required, after that, this factor remains constant. The exception for this is when the power generation is insufficient to maintain this water temperature within the required limits at any time.

It is worth noting that the performance of the system is defined by the combined effect of $\eta_{e l}$ and $\eta_{t h}$. For example, for the system configuration with 1 photovoltaic module and 2 batteries, the value of $\eta_{e l}$ is $100 \%$, which means that all the power generated by the photovoltaic modules has been used. However, when the value of $\eta_{t h}$ is $7 \%$, this means that only $7 \%$ of the total water consumption remains within the required temperature limits.

In this context, $\eta_{\text {global }}$ is the efficiency factor that best describes the system performance, since this factor considers the combined effect of the other two factors. Therefore, by analyzing the system performance through $\eta_{\text {global }}$, the conclusion is that the best design of the proposed system is with 3 photovoltaic modules and 2 batteries. This configuration has the better performance for $\eta_{\text {global }}, 84.6 \%$.

In summary, the results of the sensitivity analysis show that the best optimization for the base case is a system design with 3 photovoltaic modules and 2 batteries, which represents a $15.1 \%$ increase in the global system efficiency with respect to the base case, whose system configuration is with 2 photovoltaic modules and 2 batteries with an $\eta_{\text {global }}$ of $69.5 \%$.

\section{B. Summer Day}

One representative summer day, February 6st (from 888 $\mathrm{h}$ to $912 \mathrm{~h}$ ), was selected to present the daily summer operation of the system. In Figures 9 and 10, the temperature and electrical power profiles during the chosen day are plotted respectively.

The power loop system starts to operate at approximatively 06:00 a.m. when solar radiation begins to rise. From that time on, the battery starts to be charged until the schedule of the thermal loop system is enabled. At the moment when the thermal loop is turned on, at 07:00 a.m., the electrical power produced by PV is not enough to match the electric load of the thermal loop, for this reason the battery bank is partially discharged so that the electric load can be completely supplied. At the same time, the outlet water temperature of the tank is about to $15.4^{\circ} \mathrm{C}$ due to the tank's thermal insulation. After that, this temperature starts to drop continuously.

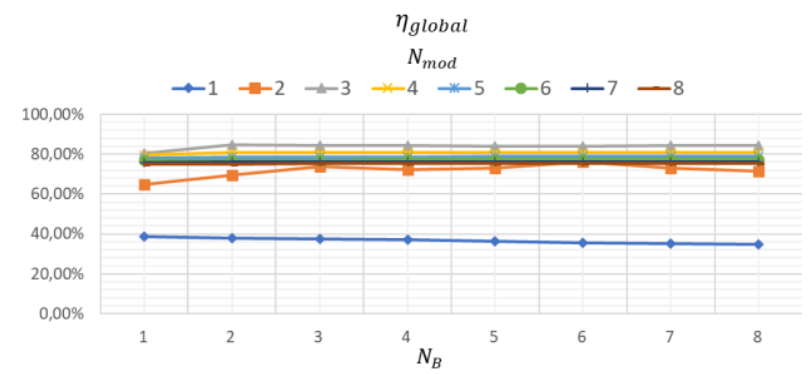

Fig. 6. Global efficiency factor.

At approximately 08:45 a.m. the electrical power produced by PV is enough to fully supply the electric load and also begin to charge the battery bank. Thus, from 8:45 am to 11:00 am, this power keeps rising and is used to cover the power required by the thermal loop and the excess is used to charge the battery bank.

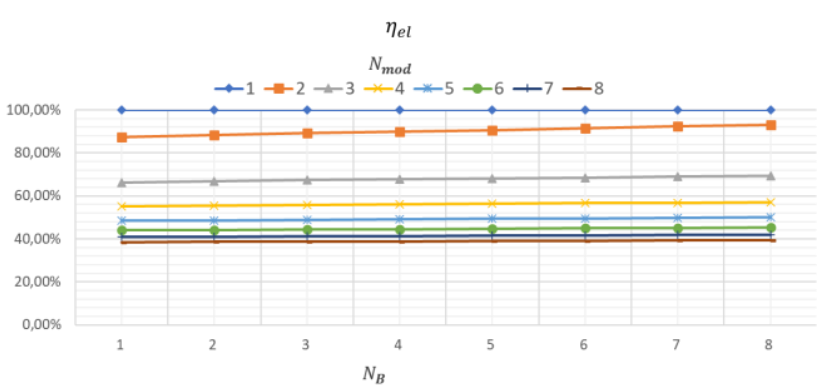

Fig. 7. Electric efficiency factor.

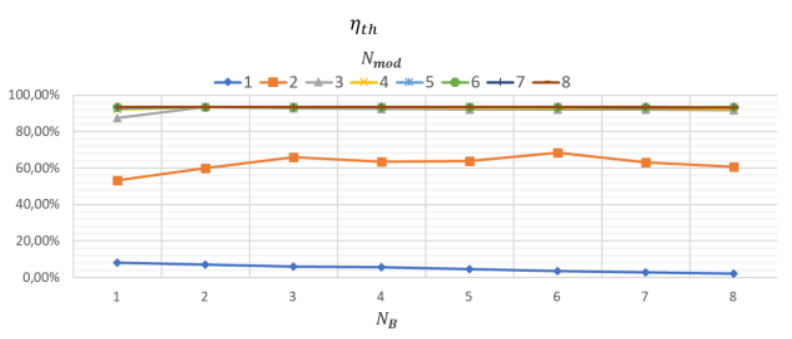

Fig. 8. Thermal efficiency factor.

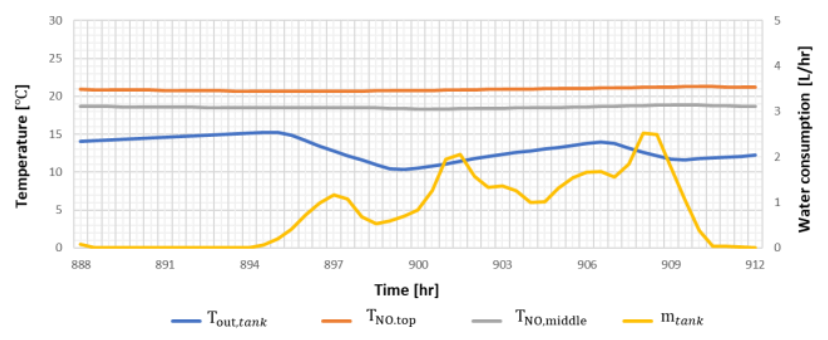

Fig. 9. Thermal stratification of the storage tank, on a summer day, 6st February (from $888 \mathrm{~h}$ to $912 \mathrm{~h}$ )

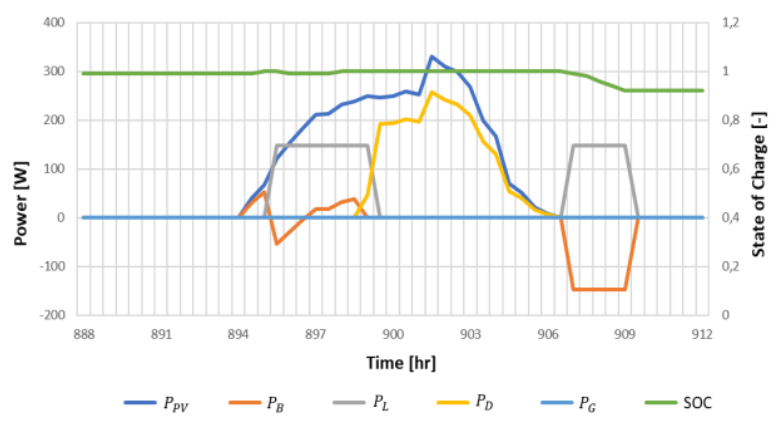

Fig. 10. Electrical powers, a summer day 6 st February (from $888 \mathrm{~h}$ to 912h)

\section{Winter Day}

In order to present the daily winter operation provided by the simulation of the system, the representative winter day of August 2nd (from $5112 \mathrm{~h}$ to $5136 \mathrm{~h}$ ) was selected. In Figures 11 and 12, the temperature and electrical power profiles over the chosen day are plotted respectively. The system operation on the winter day behaves in 4 different ways.

The first operation mode of the system occurs between 06:00 a.m. and 7:00 a.m. When solar radiation begins to rise, at approximatively 06:00 a.m., the power loop system starts to operate. During this time, all the PV power output is used to charge the battery bank. 


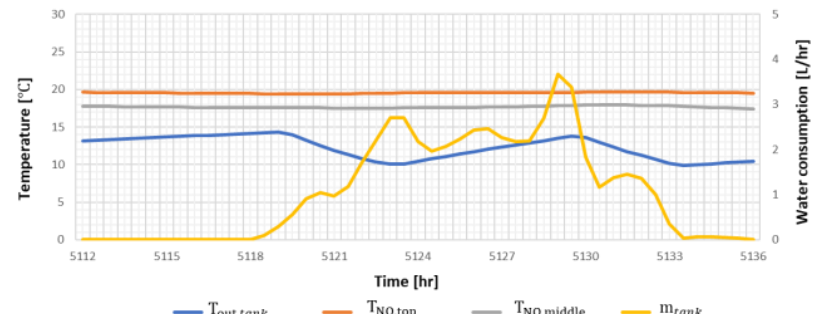

Fig. 11. Thermal stratification of the storage tank, a winter day $2 \mathrm{nd} \mathrm{Au}$ gust (from $5112 \mathrm{~h}$ to $5136 \mathrm{~h}$ ).

The first operation mode of the system occurs between 06:00 a.m. and 7:00 a.m. When solar radiation begins to rise, at approximatively 06:00 a.m., the power loop system starts to operate. During this time, all the PV power output is used to charge the battery bank.

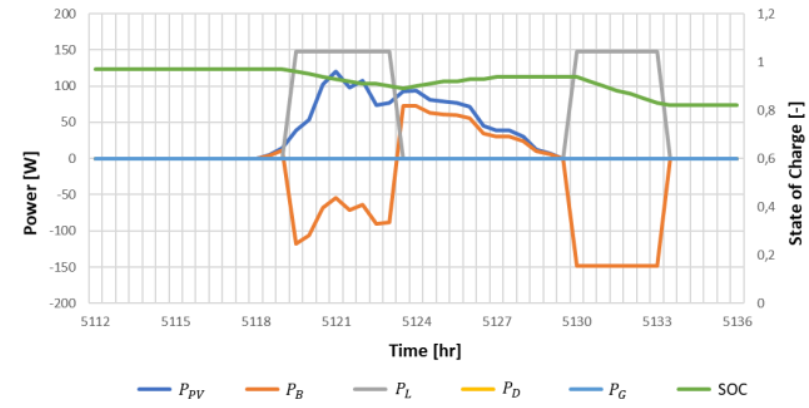

Fig. 12. Electrical powers, a winter day 2nd August (from 5112h to 5136h).

The second operation mode begins at 07:00 a.m., when the schedule of the thermal loop is enabled and the temperature of the water leaving the tank to the user is about 14.4 ${ }^{\circ} \mathrm{C}$, turning the thermal loop on, and ends at 11:00 a.m. when this same temperature reaches the lower dead band temperature, $10^{\circ} \mathrm{C}$, turning the thermal loop off. During this time, the electric load of the thermal loop is matched by the electrical power produced by the PV and the battery bank, due to the low solar radiation.

The third operation mode begins at 11:00 a.m. and ends at 5:30 p.m. when the PV power output drops to zero. During this time, all the power produced by PV is used to charge the battery bank, since the thermal loop is off, and outlet water temperature of the tank is continuously increasing.

At approximately 6:00 p.m. the thermal loop is turned on again. From that time until 8:50 p.m., the power required by the thermal loop is fully supplied by the battery bank. At 8:50 p.m. the thermal loop is turned off since the temperature of the water leaving the tank to the user reaches the lower dead band temperature, $10^{\circ} \mathrm{C}$. This operation mode is the last for the system on this representative winter day. At 9:00 p.m. the schedule of the thermal loop is disabled.

\section{Weekly Analysis}

A weekly integration was carried out to analyze the system performance over the year, through the system efficiency factors and electrical energies of the main system components presented, respectively, in Figures 13 and 14.

In Figure 14, the difference in behavior of electrical energies in the winter and summer weeks of the proposed system is shown. The energy produced by the PV is about $6.8 \%$ lower in winter weeks than in summer weeks, due to the lower incidence of total solar radiation for the same period.
Consequently, the energy self-consumed by the system is $4 \%$ more supplied by the battery bank and the excess energy of the system is $12.2 \%$ lower in the winter weeks than in the summer weeks for both.

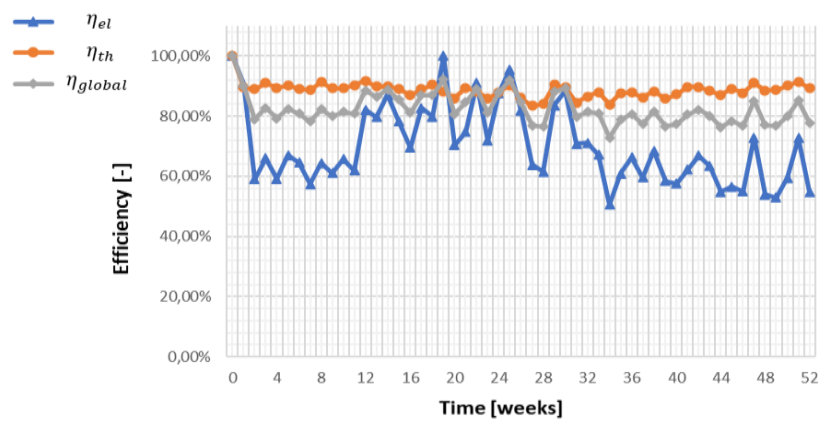

Fig. 13. System efficiency factors, weekly analysis between 1st and 52nd week of the year.

The electrical system factor grows significantly in winter weeks also because the difference in PV electric energy production between these weeks and summer ones. The thermal system factor remains almost constant throughout the weeks of the year due to the system's capacity to supply the electric load, and consequently the temperatures required by the thermal system throughout the year.

\section{E. Yearly Results}

In this section, the results of the proposed system for an annual analysis are listed in Table 3, where efficiency factors and energy flows of the investigated system are presented. These results were performed on a year integration period (from $0 \mathrm{~h}$ to $8760 \mathrm{~h}$ ).

The simulation results show that about $42.1 \%$ of the PV electric energy is consumed by the system, $33.1 \%$ is excess of energy that is not used because the system is off grid, $21.2 \%$ is used to charge the battery bank and $3.6 \%$ is lost due to the regulator efficiency.

TABLE III. ELECTRICAL ENERGIES AND SYSTEM EFFICIENCY FACTORS, YEARLY RESULTS

\begin{tabular}{cll}
\hline Parameter & Value & Unit \\
\hline $\boldsymbol{E}_{\boldsymbol{e l}, \boldsymbol{P V}}$ & 631714.8 & Wh/year \\
$\boldsymbol{E}_{\boldsymbol{e l}, \boldsymbol{B}, \boldsymbol{D I} \boldsymbol{S}}$ & 116350.0 & Wh/year \\
$\boldsymbol{E}_{\boldsymbol{e l}, \boldsymbol{D}}$ & 209311.9 & Wh/year \\
$\boldsymbol{E}_{\boldsymbol{e l}, \boldsymbol{L}}$ & 265649.6 & Wh/year \\
$\boldsymbol{P E} \boldsymbol{S}$ & 65626.8 & Wh/year \\
$\boldsymbol{\eta}_{\boldsymbol{t h}}$ & $93.4 \%$ & - \\
$\boldsymbol{\eta}_{\boldsymbol{e l}}$ & $66.8 \%$ & - \\
\hline
\end{tabular}

As regards the self-consumed energy, about $43.8 \%$ is supplied by the battery bank and $56.2 \%$ is covered by PV electrical energy. In the winter, the electric energy provided by the battery bank is needed in daylight hours for longer, due to the low solar radiation in that period.

The winter season also affects the electric system factor as in this period the PV electrical energy is almost fully selfconsumed. Thus, the low performance of this factor is due to the large difference in PV electrical energy production between the winter season and the other ones. As for thermal system factor, what this affects is the system schedule. On Monday mornings, the water temperature for the user is higher than on other days at the same time, due to the 
weekend when the system is off most of the time.

Therefore, the performance of this factor does not reach $100 \%$. However, the proposed system was able to produce 5932.7 L per year of chilled water.
The system performance with respect to energy saving achieved a $65626.8 \mathrm{Wh}$ reduction per year of primary energy consumption. This result is because the proposed system is off grid.
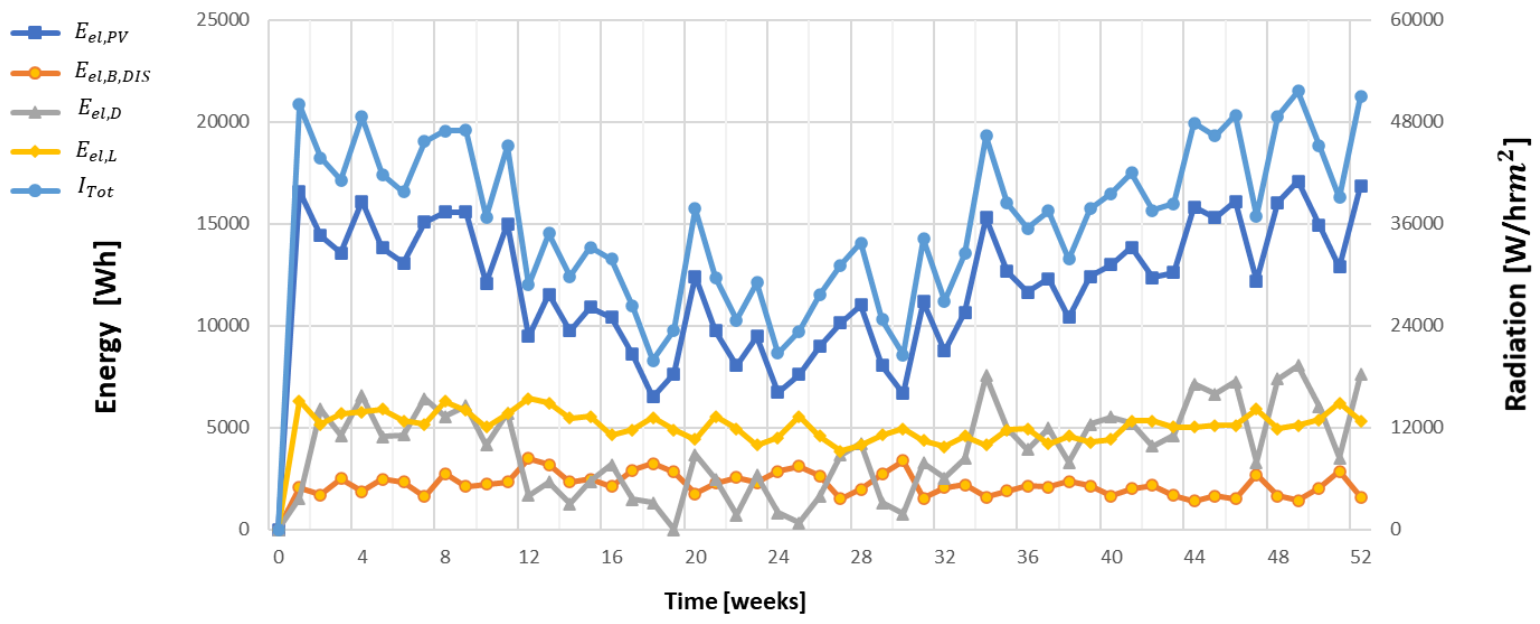

Fig. 14. Electrical energies, weekly analysis between 1st and 52nd week of the year.

\section{CONCLUSION}

The dynamic simulation model, using TRNSYS software, of a stand-alone solar photovoltaic driven drinking fountain with battery storage was designed here. Through a sensitivity analysis, the performance of the proposed system was analyzed and after that, its key design parameters were improved to provide an optimized system. The case study was implemented at the Institute Federal of Education, Science and Technology of Bahia, located in Salvador, in the northeast of Brazil.

The temperature profiles and electrical energy flows of the optimized system were investigated by means of a daily, weekly and yearly analysis. The study was completed with an analysis of primary energy saving.

The results of the dynamic simulation can be summarized as follows:

- The sensitivity analysis showed that best design for the system is with 3 photovoltaic modules and 2 batteries.

- The optimized system showed a $33.3 \%$ increase in thermal efficiency, achieving $93.41 \%$ in the ability of the system to maintain the water temperature for the user within the limits required.

- The optimized system showed a $21.31 \%$ decrease in electric efficiency due to the large difference in PV electrical energy production between the winter season and the other ones.

- The optimized system showed a $15.1 \%$ increase in the global system efficiency.

- As regards energy consumed by the optimized system, about $43.80 \%$ is supplied by the battery bank due the winter season.

- The optimized system achieves a saving of primary energy equal to about $65626.8 \mathrm{Wh}$ per year, and was able to produce $5932.7 \mathrm{~L}$ per year of chilled water.

\section{REFERENCES}

[1] A. K. Pandey, V. V. Tyagi, J. A. Selvaraj, N. A. Rahim, e S. $\mathrm{K}$. Tyagi, "Recent advances in solar photovoltaic systems for emerging trends and advanced applications", Renew. Sustain. Energy Rev., vol. 53, p. 859-884, jan. 2016, doi: 10.1016/j.rser.2015.09.043.

[2] M. D. Leonard, E. E. Michaelides, e D. N. Michaelides, "Energy storage needs for the substitution of fossil fuel power plants with renewables", Renew. Energy, vol. 145, p. 951962, jan. 2020, doi: 10.1016/j.renene.2019.06.066.

[3] M. Sevket Guney e Y. Tepe, "Classification and assessment of energy storage systems", Renew. Sustain. Energy Rev., vol. 75, p. 1187-1197, 2017.

[4] N. S. Caetano, T. M. Mata, A. A. Martins, e M. C. Felgueiras, "New Trends in Energy Production and Utilization", Energy Procedia, vol. 107, p. 7-14, fev. 2017, doi: 10.1016/j.egypro.2016.12.122.

[5] X. Wang, D. Jiang, e X. Lang, "Future extreme climate changes linked to global warming intensity", Sci. Bull., vol. $62, \mathrm{n}^{\mathrm{o}} 24$, p. 1673-1680, dez. 2017, doi: 10.1016/j.scib.2017.11.004.

[6] E. Kabir, P. Kumar, S. Kumar, A. A. Adelodun, e K.-H. Kim, "Solar energy: Potential and future prospects", Renew. Sustain. Energy Rev., vol. 82, p. 894-900, fev. 2018, doi: 10.1016/j.rser.2017.09.094.

[7] L. El Chaar, L. A. lamont, e N. El Zein, "Review of photovoltaic technologies", Renew. Sustain. Energy Rev., vol. 15, n ${ }^{\circ}$, p. 2165-2175, jun. 2011, doi: 10.1016/j.rser.2011.01.004.

[8] J. Siecker, K. Kusakana, e B. P. Numbi, "A review of solar photovoltaic systems cooling technologies", Renew. Sustain. Energy Rev., vol. 79, p. 192-203, nov. 2017, doi: 10.1016/j.rser.2017.05.053.

[9] V. Rudolf e K. D. Papastergiou, "Financial analysis of utility scale photovoltaic plants with battery energy storage", Energy Policy, vol. 63, p. 139-146, dez. 2013, doi: 10.1016/j.enpol.2013.08.025.

[10] D. Keiner, M. Ram, L. D. S. N. S. Barbosa, D. Bogdanov, e C. Breyer, "Cost optimal self-consumption of PV prosumers 
with stationary batteries, heat pumps, thermal energy storage and electric vehicles across the world up to 2050", Sol. Energy, vol. 185, p. 406-423, jun. 2019, doi: 10.1016/j.solener.2019.04.081.

[11] A. S. Joshi, I. Dincer, e B. V. Reddy, "Performance analysis of photovoltaic systems: A review", Renew. Sustain. Energy Rev., vol. 13, $\mathrm{n}^{\circ}$ 8, p. 1884-1897, out. 2009, doi: 10.1016/j.rser.2009.01.009.

[12] I. Hadjipaschalis, A. Poullikkas, e V. Efthimiou, "Overview of current and future energy storage technologies for electric power applications", Renew. Sustain. Energy Rev., vol. 13, no 6-7, p. 1513-1522, ago. 2009, doi: 10.1016/j.rser.2008.09.028.

[13] K. C. Divya e J. Østergaard, "Battery energy storage technology for power systems-An overview", Electr. Power Syst. Res., vol. 79, $\mathrm{n}^{\circ}$ 4, p. 511-520, abr. 2009, doi: 10.1016/j.epsr.2008.09.017.

[14] M. Beaudin, H. Zareipour, A. Schellenberglabe, e W. Rosehart, "Energy storage for mitigating the variability of renewable electricity sources: An updated review", Energy Sustain. Dev., vol. 14, $\mathrm{n}^{\circ}$ 4, p. 302-314, dez. 2010, doi: 10.1016/j.esd.2010.09.007.

[15] G. J. May, Alistair Davidson, e B. Monahov, "Lead batteries for utility energy storage: A review”, J. Energy Storage, vol. 15, p. 145-157, 2018.

[16] H. Chen, T. N. Cong, W. Yang, C. Tan, Y. Li, e Y. Ding, "Progress in electrical energy storage system: A critical review", Prog. Nat. Sci., vol. 19, no 3, p. 291-312, mar. 2009, doi: 10.1016/j.pnsc.2008.07.014.

[17] C. Zhang, Y.-L. Wei, P.-F. Cao, e M.-C. Lin, "Energy storage system: Current studies on batteries and power condition system", Renew. Sustain. Energy Rev., vol. 82, p. 3091-3106, 2018.

[18] R. M. Lazzarin e M. Noro, "Past, present, future of solar cooling: Technical and economical considerations", Sol. Energy, vol. 172, p. 2-13, set. 2018, doi: 10.1016/j.solener.2017.12.055.

[19] A. Allouhi, T. Kousksou, A. Jamil, P. Bruel, Y. Mourad, e Y. Zeraouli, "Solar driven cooling systems: An updated review", Renew. Sustain. Energy Rev., vol. 44, p. 159-181, abr. 2015, doi: 10.1016/j.rser.2014.12.014.

[20] A. M. Baniyounes, Y. Y. Ghadi, M. G. Rasul, e M. M. K. Khan, "An overview of solar assisted air conditioning in Queensland's subtropical regions, Australia", Renew. Sustain. Energy Rev., vol. 26, p. 781-804, out. 2013, doi: 10.1016/j.rser.2013.05.053.

[21] I. Sarbu e C. Sebarchievici, "Review of solar refrigeration and cooling systems", Energy Build., vol. 67, p. 286-297, dez. 2013, doi: 10.1016/j.enbuild.2013.08.022.

[22] K. R. Ullah, R. Saidur, H. W. Ping, R. K. Akikur, e N. H. Shuvo, "A review of solar thermal refrigeration and cooling methods", Renew. Sustain. Energy Rev., vol. 24, p. 499-513, ago. 2013, doi: 10.1016/j.rser.2013.03.024.

[23] R. Long, B. Li, Z. Liu, e W. Liu, "Performance analysis of a solar-powered electrochemical refrigerator", Chem. Eng. J., vol. 284, p. 325-332, jan. 2016, doi: 10.1016/j.cej.2015.09.021.

[24] I. Sarbu e C. Sebarchievici, "General review of solar-powered closed sorption refrigeration systems", Energy Convers. Manag., vol. 105, p. 403-422, nov. 2015, doi: 10.1016/j.enconman.2015.07.084.

[25] D. S. Kim e C. A. Infante Ferreira, "Solar refrigeration options - a state-of-the-art review", Int. J. Refrig., vol. 31, no 1 , p. 3-15, jan. 2008, doi: 10.1016/j.ijrefrig.2007.07.011.

[26] Z. Liu, A. Li, Q. Wang, Y. Chi, e L. Zhang, "Performance study of a quasi grid-connected photovoltaic powered DC air conditioner in a hot summer zone", Appl. Therm. Eng., vol. 121, p. 1102-1110, jul. 2017,

doi: 10.1016/j.applthermaleng.2017.03.132.

[27] M. J. Goldsworthy, "Building thermal design for solar photovoltaic air-conditioning in Australian climates", Energy Build., vol. 135, p. 176-186, jan. 2017, doi: 10.1016/j.enbuild.2016.11.046.

[28] Y. Li, B. Y. Zhao, Z. G. Zhao, R. A. Taylor, e R. Z. Wang, "Performance study of a grid-connected photovoltaic powered central air conditioner in the South China climate", $R e$ new. Energy, vol. 126, p. 1113-1125, out. 2018, doi: 10.1016/j.renene.2017.05.064.

[29] F. J. Aguilar, P. V. Quiles, e S. Aledo, “Operation and Energy Efficiency of a Hybrid Air Conditioner Simultaneously Connected to the Grid and to Photovoltaic Panels", Energy Procedia, vol. 48, p. 768-777, 2014, doi: 10.1016/j.egypro.2014.02.089.

[30] Y. Li, G. Zhang, G. Z. Lv, A. N. Zhang, e R. Z. Wang, "Performance study of a solar photovoltaic air conditioner in the hot summer and cold winter zone", Sol. Energy, vol. 117, p. 167-179, jul. 2015, doi: 10.1016/j.solener.2015.04.015.

[31] Y. Chen, Y. Liu, Y. Wang, D. Wang, e Y. Dong, "The Research on Solar Photovoltaic Direct-driven Air Conditioning System in Hot-humid Regions", Procedia Eng., vol. 205, p. 1523-1528, 2017.

[32] G. de Novaes Pires Leite, F. Weschenfelder, A. M. Araújo, Á. A. Villa Ochoa, N. da Franca Prestrelo Neto, e A. Kraj, "An economic analysis of the integration between air-conditioning and solar photovoltaic systems", Energy Convers. Manag., vol. 185 , p. 836-849, abr. 2019, doi: 10.1016/j.enconman.2019.02.037.

[33] A. Buonomano, F. Calise, e M. Vicidomini, "Design, Simulation and Experimental Investigation of a Solar System Based on PV Panels and PVT Collectors", Energies, vol. 9, $\mathrm{n}^{\circ}$ 7, p. 497, jun. 2016, doi: 10.3390/en9070497.

[34] "Klein, S.A.; Beckman, W.A.; Mitchell, J.W.; Duffie, J.A.; Duffie, N.A.; Freeman, T.L.; MItchell, J.C.; Braun, J.E.; Evans, B.L.; Kummer, J.P.; et al. TRNSYS. A Transient System Simulation Program; University of Wisconsin: Madison, WI, USA, 2006".

[35] F. Calise, R. D. Figaj, e L. Vanoli, "A novel polygeneration system integrating photovoltaic/thermal collectors, solar assisted heat pump, adsorption chiller and electrical energy storage: Dynamic and energy-economic analysis", Energy Convers. Manag., vol. 149, p. 798-814, out. 2017, doi: 10.1016/j.enconman.2017.03.027.

[36] A. Shirazi, R. A. Taylor, S. D. White, e G. L. Morrison, "Transient simulation and parametric study of solar-assisted heating and cooling absorption systems: An energetic, economic and environmental (3E) assessment", Renew. Energy, vol. 86, p. 955-971, fev. 2016, doi: 10.1016/j.renene.2015.09.014.

[37] A. Lake e B. Rezaie, "Energy and exergy efficiencies assessment for a stratified cold thermal energy storage", Appl. Energy, vol. 220, p. 605-615, jun. 2018, doi: 10.1016/j.apenergy.2018.03.145.

[38] MASTERFLUX, "CASCADE17-0231Y1". ago. 03, 2017, [Online]. Disponível em: www.masterflux.com.

[39] Agência Nacional de Energia Elétrica, ANEEL, "Perdas de Energia". nov. 25, 2015, [Online]. Disponível em: www.anaeel.gov.

[40] DANICA, "Divisão Supermercados e Câmaras Frigoríficas Comerciais". jul. 2012, [Online]. Disponível em: www.danica.com.br.

[41] Gas Servei, "Properties of refrigerant R134a. Technical data sheet." [Online]. Disponível em: www.gas.servei.com.

[42] M. S. Behzadi e M. Niasati, "Comparative performance analysis of a hybrid PV/FC/battery stand-alone system using different power management strategies and sizing approaches", Int. J. Hydrog. Energy, vol. 40, n ${ }^{\circ} 1$, p. 538-548, jan. 2015, doi: 10.1016/j.ijhydene.2014.10.097.

[43] Aalco Metals Ltd, "Stainless Steel Grade 316 / 1.4401". July 21, 2020, [Online]. Disponível em: http://www.farnell.com/datasheets/26035.pdf. 
[44] Johnson Controls, "Manual Técnico Bateria estacionária FREEDOM". 072008

\section{BIOGRAPHIES}

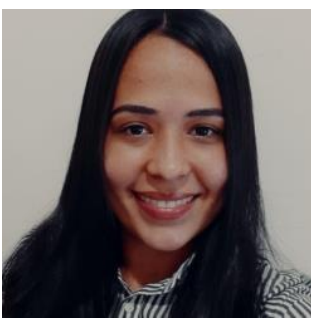

Roberta Penina Souza is an undergraduate student in Mechanical Engineering at the Federal Institute of Bahia - Brazil and a member of the ASHRAE Salvador Student Branch. Roberta inherently understands that sustainable development is an urgent need to shape our world for the better. Therefore, her research interests involve topics such as Sustainable Energy, Efficient HVAC-R Systems and Energy Storage.

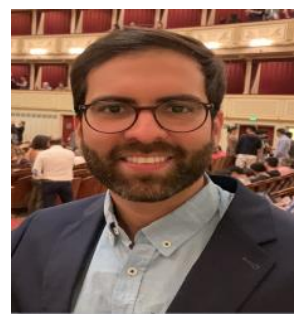

Luis Gabriel Gesteira is Professor of Thermal Sciences at the Federal Institute of Bahia - Brazil and Ph.D. researcher in Renewable Energy at the University of Zaragoza - Spain. Professor Gesteira holds Master Degrees in Industrial Engineering and Business Administration. He is graduated in Mechanical Engineering and Physics. His field of study is renewable energy simulation. The other research interest and activities involve the following topics: HVAC-R, combustion, exergy, and optimization

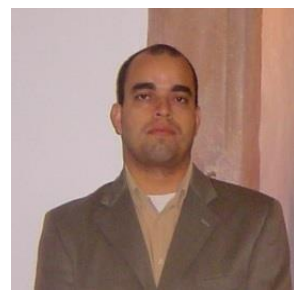

Antonio Gabriel Souza Almeida is graduated and holds Master Degree in Mechanical Engineering. He holds Phd in Energy and Environment. He is professor and researcher at the Federal Institute of Bahia - Brazil. His field of study and research interest involve the following topics: Refrigeration, Air Conditioning, Energy Efficiency, Renewable Energy and Product Development. 